\title{
AIDS-Related Stigma as a Barrier to HIV and AIDS Prevention, Care and Treatment in South African Public Universities
}

\author{
Blessing Mbatha \\ PhD in Information Science, Department of Communication Science, University of South Africa \\ E-mail: mbathbt@unisa.ac.za
}

Doi:10.5901/mjss.2013.v4n14p517

Abstract

This study set out to describe the prevalence and nature of AIDS-related stigma in selected South African public universities. The study adopted a qualitative approach by conducting in-depth interviews with its target population. The data was analysed using open coding, where dominant themes from the discussions were identified. The findings show that stigmatisation of people living with AIDS is a key obstacle to HIV prevention and AIDS care. The HIV and AIDS-related stigma places a major psychosocial burden on patients. Therefore, efforts to reduce this stigma should be an integral part of all HIV and AIDS programmes in tertiary institutions. Policies need to be developed to support individuals living with HIV and AIDS and research needs to be conducted to find innovative solutions to health problems.

Keywords: HIV; AIDS; stigma; tertiary institutions; HIV prevention; AIDS treatment, discrimination

\section{Introduction and Background}

AIDS-related stigma has been reported to be a major factor contributing to the spread of HIV (Airhihenbuwa et al., 2009; Campbell et al., 2011; Tomaszewski, 2012; Ramirez-Valles, Molina, \& Dirkes, 2013). Many researchers have written extensively on AIDS-related stigma and concur that, for the past several years, diverse and often confused concepts of this stigma have been invoked in discussions on AIDS (Castro \& Farmer, 2005; Parker \& Aggleton, 2003). Some have argued compellingly that AIDS-related stigma acts as a barrier to voluntary counselling and testing (Parker \& Aggleton, 2003). However, Castro and Farmer (2005) argue that less compelling are observations regarding the source of this stigma or its role in decreasing interest in HIV care. Goffman (1963) contends that both the fear of people who are different and the fear of disease can lead to social stigmatisation. Parker and Aggleton (2003) point out that, globally, there has been a recent resurgence in interest in HIV and AIDS-related stigma and discrimination, triggered at least in part by growing recognition that negative social responses to the epidemic remain pervasive even in seriously affected communities.

The study sought to establish whether AIDS-related stigma does indeed stand as a ranking impediment to HIV and AIDS treatment, care and support in South African public universities in the KwaZulu-Natal province. The study intended to provide government, the education sector, policy makers, AIDS activists, researchers and health professionals with information that may assist them in their decision-making processes and help them take appropriate action with regard to intervention programmes. To achieve the stated aim, the study set out to answer the following research question: Does AIDS-related stigma affect HIV and AIDS treatment, care and support?

The problem that was investigated in this study pertains to the fact that much has been said about HIV and AIDS and its consequences. However, far less attention has been paid to the obstacles to HIV treatment, care and support resulting from HIV-related stigma and discrimination in South African public universities. The epidemic of fear, stigmatisation and discrimination has undermined the ability of individuals, families and societies to protect themselves and provide support and reassurance to those affected. This, in no small measure, hinders efforts at stemming the epidemic. It complicates decisions about testing, disclosure of status, and ability to negotiate prevention behaviours, including the use of family planning services (International Centre for Research on Women, 2005). The problem in this study stems from South Africa's HIV and AIDS infection rate which is one of the highest in the world (Avert, 2013; Mbatha 2009; Vearey et al., 2011). It is important to note that the impact of HIV and AIDS on the educational sector has not gone unnoticed.

A study conducted by the World Bank (2000) assessing seven universities in six countries, including South Africa, established that HIV and AIDS have a serious impact on universities in that the epidemic affects the number of students 
that are available to study at tertiary institutions. In addition, the attrition rate due to death, illness, financial constraints and the demand for home-based care (for infected family members and dependent children) reduces enrolment numbers. In his study, Diedericks (2003) cautions that this affects the sustainability of universities and decreases the intellectual commodity. This, in turn, has a negative impact on the economy as only countries that improve their educational productivity and deliver an adequate number of competent graduates to the labour market will improve their wealth-creating abilities and thus prosperity for all. Likewise, Mkhize (2008) argues that HIV and AIDS may also reduce the quality of education and could further widen the gender gap in education as female students are more adversely affected than are males. Mkhize (2008) further cautions that many students will have to take time off to nurse the sick, seek medical care and attend funerals, which may result in their missing classes or even terminating their studies. In their book on HIV-related stigma across contexts, Ogden and Nyblade (2005) concur with Airhihenbuwa et al. (2009) and Campbell et al. (2011) that HIV and AIDS-related stigma and discrimination together have long been recognised as one of the main obstacles to the prevention, care, and treatment of HIV and AIDS. The last mentioned authors vehemently contend that very little has been done on a large scale to combat the stigma. They believe that there are various reasons for this inaction, including the belief of many policymakers that stigma is hard to define and measure, making it difficult to design and implement interventions.

\subsection{Stigma defined}

Alonzo and Reynolds (1995) describe stigma as a social construction that significantly affects the lives and experiences of individuals living with HIV infection, as well as their partners, families and friends. AIDS-related stigma and discrimination refer to prejudice, negative attitudes, abuse and maltreatment directed at people living with HIV and AIDS (Avert, 2013). The consequences of stigma and discrimination are wide-ranging. These include being shunned by family, peers and the wider community, poor treatment in health care and education settings, an erosion of rights, psychological damage, and a negative effect on the success of HIV testing and treatment (Avert, 2013). Likewise, Parker and Aggleton (2003) are of the view that the decision to disclose HIV status is therefore the outcome of a calculation of the immediate benefits and risks of such an action. However, traditional definitions underplay the role of stigma as a social and political construction that facilitates the domination of certain social groupings, especially in the context of competition for scarce resources. In line with the aforementioned views, Link and Phelan (2001), supported by Van Dijk and Van Driel (2012), opine that social science research on stigma has grown significantly over the past two decades, particularly in social psychology where researchers have elucidated the ways in which people construct cognitive categories and link those categories to stereotyped beliefs. Link and Phelan (2001) further assert that, amidst this growth, the stigma concept has been criticised as being too vaguely defined and too individually focused. In response to these criticisms, Link and Phelan (2001) define stigma as the co-occurrence of its components - labelling, stereotyping, separation, status loss and discrimination - and further indicate that, for stigmatisation to occur, power must be exercised. Likewise, an earlier study by Alonzo and Reynolds (1995) defines stigma as a social construction which dramatically affects the life experiences of individuals infected with HIV, as well as those of their partners, families and friends. Also, Herek (1999), supported by Lekas, Siegel and Leider (2011), describes AIDS-related stigma as prejudice, discounting, discrediting and discrimination directed at people perceived to have AIDS or HIV, and at the individuals, groups and communities with which they are associated.

\section{Literature Review}

Data about the stigmatisation of persons living with HIV and AIDS in South African public universities is scant. The literature shows that many diseases have been stigmatised throughout history. For example, persons with the plague were stigmatised during the Middle Ages, and sexually transmitted diseases have been stigmatised throughout the last several centuries (Brandt, 1987). Likewise, Parker and Aggleton (2003) argue that AIDS has been one of the most feared and stigmatised diseases of the last 20 years. In support of Parker and Aggleton (2003), Ogden and Nyblade (2005) note that there is abundant evidence that the stigmatisation of AIDS has been detrimental to the health of those with AIDS and has played a role in limiting public health and medical efforts to control the disease. Another important point worth noting is that early stigmatisation of AIDS as a disease of homosexual men contributed to the low levels of funding for AIDS research in the 1980s (Shilts, 1987). Parker and Aggleton (2003) assert that the theoretical literature emphasises that stigma results not only from fear of physical contagion but also from fear of "symbolic contagion", a threat to both the health and wellbeing of individuals and to the wellbeing and legitimacy of the status quo. Whereas the form and content 
of stigma will vary from one context to another, various forms of stigma are united by the way in which they serve to support systems of social inequality and social difference and to reinforce the interests of powerful social actors seeking to legitimise their dominant status (Parker \& Aggleton, 2003).

Snyder, Omoto and Crain (1999) argue that, occasionally, these fears co-occur, resulting in severe stigmatisation of strangers with diseases. Such stigmatisation can increase the adverse consequences of a disease in multiple ways. First, stigmatisation can substantially increase the suffering of persons with the disease. Second, persons with or at risk for the disease may avoid seeking health care, making it much harder for public health authorities to control the disease. Third, professionals and volunteers working in the field may also become stigmatised, leading to higher rates of stress and burnout. Finally, stigmatisation may generate considerable economic losses if people avoid groups or geographic areas associated with the disease. Fear of contagion coupled with negative, value-based assumptions about people who are infected lead to high levels of stigma surrounding HIV and AIDS. UNAIDS (2008) outlines factors that contribute to AIDS-related stigma and these include the following:

- HIV and AIDS are life-threatening diseases, and therefore people have strong reactions to them.

- HIV infection is associated with behaviours (such as homosexuality, drug addiction, prostitution or promiscuity) that are already stigmatised in many societies.

- Most people become infected with HIV through sex, which often carries moral baggage.

- There is much inaccurate information about how HIV is transmitted, creating irrational behaviour and misperceptions of personal risk.

- HIV infection is often thought to be the result of personal irresponsibility.

- Religious or moral beliefs lead some people to believe that being infected with HIV is the result of moral fault (such as promiscuity or "deviant sex") that deserves to be punished.

- The effects of antiretroviral therapy on people's physical appearance can result in forced disclosure and discrimination based on appearance.

Valdiserri (2002), supported by Herek, Mitnick and Burris (1998), argues that stigma is not new to public health, nor is it unique to HIV and AIDS. Duffy (1990) observes that those who became ill with cholera in the early years of the American republic were publicly decried as intemperate, lazy and vice-ridden. An earlier study by Brandt (1987) established that, even after the germ theory had become widely accepted - thus discrediting divine wrath, miasma and other incorrect theories of disease - negative attitudes lingered. For example, some persons with syphilis were seen as "innocent"; others were not. Often, physicians were reluctant to treat patients in the last mentioned category, considering them to be immoral and hence unworthy of care.

\section{Research Methodology}

The study targeted students in three out of five purposively selected South African public universities in the KwaZuluNatal province. The study adopted a qualitative approach by conducting focus group interviews in order to engage and encapsulate the different viewpoints of its target population. The target population, which consisted of a total of 150 students from all targeted universities, was stratified according to its level of study. Five groups per institution were selected for the focus group interviews. Using simple random sampling, 50 students from each university were selected. The interviews provided the students with an opportunity to share and reflect on their perceptions and experiences of AIDS-related stigma. The data were analysed using open coding, where dominant themes from the discussions were identified and discussed in detail. The study sought to generate a rich body of findings from a relatively small number of respondents rather than less detailed information from a relatively larger group. While the study's findings may not be representative or generalisable, they indicate areas for further exploration and contribute to the development of strategies that can be implemented to combat the pandemic. In terms of ethical consideration, informed consent was obtained from each participant in the study in order to ensure that all participants understood what they were doing and to verify their willingness to participate. The respondents were assured of their rights, including the right of consent, protection from disclosure of information, and respect for their privacy. All the research participants participated voluntarily and were not forced to take part in the study. With regard to protection from harm, the researcher ensured that the participants were not at any risk and would not be exposed to embarrassment, unusual stress, or any demeaning treatment. Anonymity and confidentiality were promised and maintained. The information they provided was not made available to anyone else not directly involved in the study and cannot be traced to or used to identify the participants. The researcher also ensured that the participants would remain anonymous throughout the study. 


\section{Findings}

The findings are discussed under the following headings: demographic profile of the respondents, HIV-related stigma, internalised stigma and stigmatised places.

\subsection{Demographic profile of the respondents}

The findings indicate that the sample was racially biased with 111 (74\%) indigenous Africans and 39 (26\%) Indians. The sample also represented a broad spectrum of ages, with 109 (73\%) respondents being between 18 and 22 years of age, $24(16 \%)$ between 22 and 25 years of age, $9(6 \%)$ between 25 and 30 years of age, and only $8(5 \%)$ being 30 and older. Further, a significant number (101 or 67\%) of participants were from urban areas while $49(33 \%)$ were from rural areas. In the study a significant number (97 or $65 \%$ ) were female, while $53(35 \%)$ were male.

\subsection{HIV-related stigma}

HIV-related stigma and discrimination are obstacles that severely hamper efforts to effectively fight the HIV and AIDS epidemic. Fear of discrimination often prevents people from seeking treatment for AIDS or from publicly admitting their HIV status. Thus, the study set out to establish whether this was the case at all the tertiary institutions forming part of the study. The respondents had the following to say:

- It is well known that some people normally discriminate against the one who is sick and has disclosed his/her status.

- A friend of mine disclosed her HIV status to her roommate, and then her roommate refrained from sharing utensils with her.

- If you have a virus, some students do not even want to enter your room.

- I have never tested on this campus because I am scared of stigma.

- Some HIV-positive students hide their status because they fear that students will laugh at them.

- If you are HIV positive, people think that you are immoral.

- If you are HIV positive, people think that you contracted it by sleeping around.

- It's because it's perceived as a sexually transmitted disease. Therefore when we talk about HIV people, we always refer to them as people who flirt.

- People fear disclosing this disease as it is contracted through sex. People's perception is that people who are infected with the HIV virus are not well behaved.

- Eish, it is difficult here because if you visit the clinic people think you are HIV positive.

- Even if I were HIV positive I would not visit the clinic due to the stigma attached.

- If you visit the clinic here, students think that you have a problem or that maybe you see HIV symptoms in your body.

- The nurses who work here gossip about people who come to the clinic; it is even worse because some are student assistants and they still see us in that light.

- If you go for an HIV test, students think that you sleep around and that maybe you also have some HIV symptoms. Then they start gossiping about you and it is even worse if you are a Christian as some people think that Christians cannot be infected.

- Some health workers are nursing students, so a friend of mine who is living with HIV was reluctant to visit the campus health services out of concern for this not remaining confidential.

- Here many students prefer to go to off-campus clinics for HIV tests or anything related to STIs rather than risk being identified as HIV positive on this campus.

- The main problem here is that students don't want to disclose their HIV status because they are afraid that other students will discriminate against them.

- I heard that a student tried to commit suicide after knowing that he was HIV positive. When the warden asked him why he wanted to kill himself, he said he was afraid that other students were going to judge him. 


\subsection{Internalised AIDS stigma}

HIV and AIDS are perhaps the most stigmatised medical condition in the world. The respondents were asked to comment on their perceptions and experiences of internalised AIDS stigma on their campuses. This is what they had to say:

- If I were HIV positive, I think it would be difficult for me to reveal my HIV infection.

- I would feel like I am being irresponsible to myself and to my loved ones.

- Being HIV positive would make me feel dirty, so I won't test.

- I would have to be responsible for my actions and do the right thing, which is to stay healthy.

- I feel guilty that I am HIV positive.

- My parents have invested a lot in me and that is why I am here; maybe I would just kill myself.

- My parents taught me a lot about how I should behave here because I am now responsible for myself and they are not around, so I would be a disgrace to them.

- I would feel worthless if I happened to be HIV positive.

- It would be my own fault that I am HIV positive, so I would have to face it and not hide it.

- For fear of discrimination and stigma, I would definitely hide my HIV status from others.

- I am afraid that if I am HIV positive I might be rejected and mistreated by my fellow students and friends.

- Notwithstanding the fact that our university does provide care and support services for people infected and affected with HIV and AIDS, I am still not brave enough to go for an HIV test. You see, I lost a friend of mine soon after he had done an HIV test. He died two weeks later after sleepless nights, thinking about death and stigma.

\subsection{Stigmatised places}

Specially allocated Voluntary Counselling and Testing and HIV and AIDS treatment rooms can prevent uptake of treatment as people may fear being identified as being HIV positive (Population Council and Health Systems Trust, 2006). In this regard, the study sought to establish whether this was the case at the universities under investigation. The respondents had the following to say:

- Eish. The problem here is that our campus clinic is too small, so there is no privacy. For example, if you go for an HIV test and your results come back positive, everybody is able to guess the outcome of the test from your body language as you have to pass the very same queue you were in. There is only one entrance which is also the only exit and this severely affects the number of students who want to do an HIV test.

- My problem is that there is absolutely no privacy as the VCT room is right in the middle of the clinic. It is very uncomfortable, as people in the clinic can all see the people who go into the VCT room, after which they will gossip and say, "Did you see Mr X coming from the VCT room?"

- The main problem for me is that the clinic here is the most stigmatised place. If you go there just for flu medication, people think that you are HIV positive and they start gossiping and saying all sorts of things. So I will never visit the campus clinic.

- I I am scared to be seen by other students because some of the clinic staff are students.

- The nurses who work here gossip about people who come to the clinic. They even mention a person's name if they are talking. They say we saw so and so at the clinic and he/she was checking for "that thing".

\section{Discussion}

The findings of this study concur with the study by Simbayi et al. (2007) who caution that AIDS-related stigma can lead to discrimination such as negative treatment and denied opportunities on the basis of people's HIV status. Li et al. (2012) support the findings of the study by arguing that stigma is indeed a significant barrier to HIV prevention and treatment across the globe. Petros at al. (2006) take the argument further by pointing out that discrimination as a result of stigma can affect all aspects of a person's daily life, for example when they wish to travel, use healthcare facilities or seek employment. Duffy (1990) also argues that the knowledge that a disease caused by HIV infection (whose acquisition is prominently associated with sexual and drug-using behaviour) is capable of provoking intense, value-laden reactions such as those described above is, perhaps, not surprising. In their study on internalised stigma, Simbayi et al (2007) 
established that AIDS stigma interferes with HIV prevention, diagnosis and treatment and can become internalised by people living with HIV and AIDS. Sharing similar sentiments, Herek (1999) is of the view that people with HIV infection are often ascribed responsibility for their condition because HIV is contracted from behaviours that are considered avoidable, namely unsafe sex and drug-use practices.

Many researchers, such as Chesney and Smith (1999) and Parker and Aggleton (2003), have written extensively on internalised AIDS stigma and cautioned that it has the potential to bring about adverse behavioural and emotional ramifications - including not seeking treatment and care services, engaging in unsafe sex practices, fostering a sense of isolation and emotional distress, and self-hatred. In strengthening these views, Parker and Aggleton (2003) caution that AIDS stigma also reproduces inequalities of class, race and gender. In their study on internalised AIDS stigma, Kalichman and Simbayi (2003), supported by Petros et al. (2006), established that, in the South African context, AIDS stigma also creates a barrier to HIV prevention - and that this includes HIV testing and counselling. Paxton (2002) also opines that disclosure of HIV infection can be an extremely difficult process because it makes one vulnerable to the perceived stigma of friends, family or the community. Rohleder and Gibson (2005) observe that stigma makes HIV positive individuals reluctant to become identified and seek appropriate care, which ultimately results in a lack of access to important resources such as family and social support. Parker and Aggleton (2003), supported by Joffe and Begetta (2003), argue that, in South Africa, the Treatment Action Campaign has opened up the exciting possibility of collective action on the part of people with AIDS. Those concerned engage in many high-profile actions highlighting the ways in which people's lives are blighted by various forms of interpersonal stigma and institutional discrimination. The findings above show that campus clinics are regarded as stigmatised places in tertiary institutions and this has affected the fight against the spread of HIV and AIDS. The findings further indicate that lack of space is compromising the confidentiality of VCT and is acting as a deterrent against testing and the receiving of counselling. These findings concur with those of the Population Council and Health Systems Trust (2006) which reports that stigma is a key barrier to HIV and AIDS care, to treatment, to prevention programmes and to their impact on social support systems.

\section{Conclusion}

This study was conducted in South African public universities in the KwaZulu-Natal province and assessed the prevalence of AIDS-related stigma in those universities as a barrier to HIV and AIDS care, treatment and support. The AIDS epidemic is different from any other epidemic the world has faced. As such, it requires a response from the global community broader and deeper than has ever before been mobilised against a disease. The fact that AIDS-related stigma exists and needs redress is incontestable. It is evident from the findings of this study that stigmatisation of people living with AIDS is a key obstacle to HIV prevention and AIDS care. Indeed, it is now generally accepted that efforts to reduce stigma should be an integral part of all HIV and AIDS programming in tertiary institutions. It is also clear from the findings that HIV and AIDS-related stigma places a major psychosocial burden on patients. Therefore, stigma and discrimination should be addressed through strong protection being put in place to ensure confidentiality, and through emotional support and cultural sensitivity. In each of the universities targeted, stigma was also reported to be strongly associated with visiting certain health facilities, including VCT and ARV treatment sites. Fear of stigma and discrimination were shown to be deterring people from undergoing testing and consultation. This, in turn, was shown to be resulting in delays in patients knowing their HIV status and in commencing with treatment where treatment was necessary.

AIDS-related stigma is also perpetuated by the fact that some people living with HIV lack knowledge of their rights in society. In this respect, education is needed so that they are able to challenge the discrimination, stigma and denial that they encounter. It is also worth mentioning that institutional and other monitoring mechanisms can enforce the rights of people with HIV and provide powerful means of mitigating the worst effects of discrimination and stigma. Having said this, it is also true that no policy or law can, by itself, combat HIV- and AIDS-related discrimination. Stigma and discrimination will continue to exist as long as societies as a whole have a poor understanding of HIV and AIDS and the pain and suffering caused by negative attitudes and discriminatory practices. The fear and prejudice that lie at the core of AIDS-related discrimination need to be tackled at community and national levels, with AIDS education playing a crucial role. It is also important to note that, when confronting the negative impact of HIV- and AIDS-related stigma on tertiary institutions' efforts, government, researchers, AIDS activists and tertiary institutions should continue to support research in the domains of intervention programmes, policy formulation and research that will add to people's understanding of how stigma hampers society from effectively responding to HIV and AIDS. In response to HIV and AIDS in tertiary institutions, students and staff need to be empowered about health issues; students need to be mobilised to solve health problems; policies and plans need to be developed in support of those individuals living with HIV and AIDS; and research 
needs to be conducted to find innovative solutions to health problems. Taking the opportunity to design and implement interventions that address these common issues and understandings will be a logical first step in reversing the devastating impact that stigma is having on those infected with and affected by HIV and AIDS. It is clear that stigmarelated violence - or even the fear of violence - prevents many people from seeking HIV testing, from returning to hear their results, or from securing treatment, possibly turning what could be a manageable chronic illness into a death sentence and perpetuating the spread of HIV.

\section{References}

Airhihenbuwa, C., Okoror, T., Shefer, T., Brown, D., Iwelunmor, J., Smith, E.D., Adam, M., Simbayi, L., Zungu, N., Dlakulu, R., \& Shisana, O. (2009). Stigma, culture, and HIV and AIDS in the Western Cape, South Africa: an application of the PEN-3 cultural model for community-based research. Journal of Black Psychology, 35(2), 407-432.

Alonzo, A.A., \& Reynolds, N.R. (1995). Stigma, HIV and AIDS: an exploration and elaboration of a stigma trajectory. Social Science \& Medicine, 41(3), 303-315.

Avert (2013). Sex education that works. Retrieved on June 2013, 2013 from the following Website: http://www.avert.org/sexeducation.htm\#references

Brandt, A. M. (1987). No magic bullet: a social history of venereal disease in the United States since 1880. Expanded edition. New York: Oxford University Press.

Campbell, C., Skovdal, M., Madanhire, C., Mugurungi, O., Gregson, S., \& Nyamukapa, C. (2011). "We, the AIDS people...": how antiretroviral therapy enables Zimbabweans living with HIVIAIDS to cope with stigma. American Journal of Public Health, 101(6), 1004-1010.

Castro, A., \& Farmer, P. (2005). Understanding and addressing AIDS-related stigma: from anthropological theory to clinical practice in Haiti. American Journal of Public Health, 95(1), 53-59.

Chesney, M.A. \& Smith, A.W. (1999). Critical delays in HIV testing and care: the potential role of stigma. American Behavioral Scientist, 427, 1162-1174.

Diedericks, A. (2003). University students' HIVIAIDS knowledge, information, sexual behaviour and perceptions of Voluntary Counselling and Testing (VCT). University of Port Elizabeth: South Africa.

Duffy, J. (1990). The sanitarians: a history of American public health. Urbana: University of Illinois Press.

Goffman, E. (1963). Stigma: notes on the management of a spoiled identity. New York: Simon \& Schuster.

Herek, G.M. (1999). AIDS and stigma. American Behavioral Scientist, 42(7), 1106-1116.

Herek, G.M., Mitnick, L., \& Burris, S. (1998). Workshop report. AIDS and stigma: a conceptual framework and research agenda. AIDS Public Policy Journal, 13(1), 36-47.

International Centre for Research on Women (2005). HIV-related stigma across contexts: common at its core. Retrieved on June 12 , from the following Website: http://www.icrw.org/publications/common-its-core-hiv-related-stigma-across-

Joffe, H., \& Begetta, N. (2003). Social representations of AIDS among Zambian adolescents. Journal of Health Psychology, 8, 616-631.

Kalichman, S.C., \& Simbayi, L.C. (2003). HIV testing attitudes, AIDS stigma, and voluntary HIV counselling and testing in a black township in Cape Town, South Africa. Sexually Transmitted Infections, 79(6), $442-447$.

Lekas, H., Siegel, K., \& Leider, J. (2011). Felt and enacted stigma among HIV/HCV-coinfected adults: the impact of stigma layering. Qualitative Health Research, 21(9), 1205-1219.

Li, X., Wang, H., He, G., Fennie, K., \& Williams, A.B. (2012). Shadow on my heart: a culturally grounded concept of HIV stigma among Chinese injection drug users. Journal of the Association of Nurses in AIDS Care, 23(1), 52-62.

Link, B.G., \& Phelan, J.C. (2001). Conceptualizing stigma. Annual Review of Sociology, 27, 363-385.

Mbatha, B.T. (2009). Barriers that impede the effectiveness of precautionary measures of combating the spread of HIV and AIDS: the case of the University of Zululand and Mangosuthu University of Technology. Journal of Humanities and Social Sciences, 1(1), 43-50.

Mkhize, N. (2008). An appreciative inquiry of the voluntary counselling and testing (VCT) program of the University of Zululand. Dissertation, KwaDlangezwa, University of Zululand, South Africa.

Ogden, J., \& Nyblade, L. (2005). Common at its Core: HIV-Related Stigma Across Contexts, Washing DC: International Center for Research on Women (ICRW).

Parker, R., \& Aggleton, P. (2003). HIV and AIDS-related stigma and discrimination: a conceptual framework and implications for action. Social Science \& Medicine, 57(1), 13-24.

Paxton, S. (2002). The paradox of public HIV disclosure. AIDS Care, 14, 559-567.

Petros, G., Airhihenbuwa, C.O., Simbayi, L., Ramlagan, S., \& Brown, B. (2006). HIVIAIDS and 'othering' in South Africa: the blame goes on. Culture, Health and Sexuality, 8(1), 67-77.

Population Council and Health Systems Trust. (2006). Understanding barriers to community participation in HIV and AIDS services. Summary Report. Johannesburg: Population Council.

Ramirez-Valles, J., Molina, Y., \& Dirkes, J. (2013). Stigma towards PLWHA: the role of internalized homosexual stigma in Latino gay/bisexual male and transgender communities. AIDS Education and Prevention, 25(3), 179-189.

Rohleder, P., \& Gibson, K. (2005). "We are not fresh": HIV-positive women talk of their experience of living with their spoiled identity. 
Cape Town, South Africa: Centre for Social Science Research.

Shilts, R. (1987). And the band played on: politics, people, and the AIDS epidemic. New York: St Martins Press.

Simbayi, L.C., Kalichman, S., Strebel, S., Cloete, A., Henda, N., \& Mqeketo, A. (2007). Internalized stigma, discrimination, and depression among men and women living with HIVIAIDS in Cape Town, South Africa. Social Science \& Medicine, 64, 18231831

Snyder, M., Omoto, A.M., \& Crain, A.L. (1999). Punished for their good deeds: stigmatization of AIDS volunteers. American Behavioural Science, 42, 1193-1211.

Tomaszewski, E. P. (2012). Understanding HIV and AIDS stigma, and discrimination, Human Rights Update. Washington, DC: NASW National Association of Social Workers.

UNAIDS (2008). 2008 UNAIDS Annual Report: Towards Universal Access. Retrieved on 12 July 2013, from http://data.unaids.org/pub/Report/2009/jc1736_2008_annual_report_en.pdf

Valdiserri, R. O. (2002). HIVIAIDS stigma: an impediment to public health. American Journal of Public Health, 92(3), 341-342.

Van Dijk, D., \& Van Driel, F. (2012). Questioning the use-value of social relationships: care and support of youths affected by HIV in child-headed households in Port Elizabeth, South Africa. African Journal of AIDS Research, 11(3), 283-293.

Vearey, J., Richter, M., Núñez, L., \& Moyo, K. (2011). South African HIVIAIDS programming overlooks migration, urban livelihoods, and informal workplaces. African Journal of AIDS Research, 10, 381-391.

World Bank (2000). Exploring the implications of the HIVIAIDS epidemic for educational planning in selected African countries: the demographic question. World Bank: Washington (The Galiber Report). 